\title{
Golden Rectangle Ratio - How Precious Is It? : A Clinical Study
}

\author{
Dr. Sagar C. Chaudhari. M. D. S, Dr. S. P. Dange. M. D. S ${ }^{\mathrm{b}}$, \\ Dr. Smita A. Khalikar. M.D.S . \\ Govt. Dental College \& Hospital, Aurangabad, Maharashtra,India \\ Presented at $40^{\text {th }}$ Indian Prosthodontic Society Conference \& $8^{\text {th }}$ Biennial meeting of Asian Academy of \\ Prosthodontics, Dec 2012, Chennai, India. \\ ${ }^{a}$ Post-graduate student, Dept of Prosthodontics, Govt. Dental College \& Hospital, Aurangabad, Maharashtra \\ University of Health Sciences, Maharashtra, India. \\ ${ }^{b}$ Professor \& Head, Dept of Prosthodontics, Govt. Dental College \& Hospital, Aurangabad, Maharashtra \\ University of Health Sciences, Maharashtra, India. \\ ${ }^{c}$ Associate Professor, Dept of Prosthodontics, Govt. Dental College \& Hospital, Aurangabad, Maharashtra \\ University of Health Sciences, Maharashtra, India.
}

\begin{abstract}
Maxillary central incisors are of critical value in the dental esthetics. The golden rectangle ratio concept may play a role in selecting the optimum width and length of this tooth. The aim of this study is to investigate the existence of this ratio among individuals with natural dentition and routinely used acrylic denture teeth sets and to validate its role in dental esthetics. The clinical crown length of maxillary left and right central incisor (CI) is measured, mean is calculated and combined crown width of left and right central incisors is measured. Crown width to crown length ratio of natural dentition and acrylic denture teeth sets of different manufacturers was calculated and compared with the Golden Rectangle ratio and statistically analysed. Golden rectangle was found to have a significant relationship with esthetic appearance of maxillary central incisors. The results of this study will help in proper selection of teeth for all restorative procedures.

Key words: golden rectangle proportion, esthetics,maxillary central icisors, anterior restorations, combined width of central incisors
\end{abstract}

\section{Introduction}

Anterior dento-labial esthetics is one of the prime considerations for a patient having prosthodontic treatment. One of the important aspects of dento-labial esthetics is the size and form of maxillary anterior teeth. For better esthetic results maxillary anterior teeth should be restored with optimal dento-labial relationship and in harmony with overall facial appearance.

The definition of ideal tooth dimensions, however, remains a difficult task due to individual variations and proximal or incisal tooth wear. To provide "magic numbers" for the clinicians, mathematic theorems such as "golden proportion" and "golden percentage " " have been proposed. Lombardi ${ }^{2}$ was the pioneer to suggest the application of golden proportion in dentistry in addition he described the use of "repeated ratio" in maxillary anterior teeth. Marquardt ${ }^{3}$ suggested the concept of Golden Rectangle according to which the height of central incisors is in golden proportion to combined width of maxillary central incisor having a value of 1:1.618. This study was carried out to evaluate the golden rectangle ratio in natural and acrylic denture teeth set. Levin ${ }^{4}$ also suggested the Golden proportion in dentistry and related it with successive width of anterior teeth as viewed from labial aspect. Further Mange and Belser ${ }^{5}$ observed excessive narrowness of maxillary arch and compression of lateral segments in situations where strict adherence to the golden proportion rule was followed.

\section{Materials And Methods}

A morphologic study on maxillary central incisors was carried out on patients reported to Department of Prosthodontics \& Implantology, Govt. Dental College \& Hospital, Aurangabad and on commonly available acrylic denture teeth sets.

The inclusion criteria were;

- All maxillary and mandibular anteriors should be present.

- No gingival or periodontal conditions or therapy that would undermine healthy tooth - tissue

relationship.

- Interdental spacing or crowding should be absent.

- No restored anterior teeth should be present.

- No history of orthodontic treatment.

The exclusion criteria were;

- Evidence of gingival alteration or irregularities. 
- Apparent loss of tooth structure due to attrition, fracture, caries.

In the present study evaluation of the occurrence of the golden rectangle proportion was conducted for the two maxillary central incisors, by dividing the combined width of the maxillary central incisors by the length of maxillary central incisors of natural teeth and acrylic denture teeth sets.

The study was conducted on 200 subjects within the age group of 18-25. Measurements were taken with a digital vernier caliper with sensitivity of $0.01 \mathrm{~mm}$. The width was recorded by measuring the maximum distance between the mesial and distal contact points on the tooth on the line perpendicular to long axis. Length was recorded as the longest distance from cervical gingival margins to incisal edge of the tooth on a line parallel to long axis. Length of both right and left central incisor was recorded and mean was calculated and this mean was taken as a length for further calculations.

The Golden Rectangle Ratio was then obtained by dividing the combined width by the length of the maxillary central incisors in natural dentition and acrylic denture teeth sets. The mean of natural population obtained. Mean of artificial acrylic denture teeth sets of each brand was obtained. The calculated values were compared with the expected golden rectangle ratio values of the related teeth.

\section{Results}

The data collected from 200 subjected (93 males, 107 females) revealed that range of combined width to length ratio of clinical crown of maxillary central incisors was $1.473-1.804$. The same ratio was obtained from acrylic denture teeth sets and then both were compared with the golden rectangle ratio.

\section{Discussion}

Genetic variation is the basis of vast diversity among the population. So the information regarding tooth norms is valuable in a group of population to achieve better esthetics during oral rehabitilation and denture fabrication as it influences the overall esthetic value of smile.

Owens $^{6}$ et al measured the width of maxillary central incisors in several racial groups and noted variation in most of them, with males having wider central incisor than females. In this study no such differences were seen. This study also analysed the measurements of acrylic denture teeth sets.

Sterrett $^{7}$ et al. also performed same kind of study using the maxillary central incisors width to length ratio. Marquardt found the ratio of combined width to length 1.618. Sterrett also observed the same results as that of Marquardt. Both of them found gender variation with males having greater width and length as compared to females in different racial groups.

In the present study, no statistically significant differences were seen between two genders. On observation it was found that individuals with higher width to length ratio had broader or square central incisors and individuals with lower width to length ratio had longer and narrower central incisors. This study also had a similar result with slight variation $(+3 \%)$ from $1.618(1.634+0.065)$.

During the study, the golden rectangle ratio of various routinely used artificial acrylic denture teeth sets were calculated. Mean for each brands was obtained. So, it was seen that most of the teeth sets fell within the range of +/- $1 \mathrm{SD}$. All brands used in study fell in +/- $2 \mathrm{SD}$.

\section{Conclusion}

- The maxillary central incisor is the dominant element of anterior dental composition and hence should be restored or replaced with proper proportion of width and length for better esthetic results.

- $80 \%$ of the subjects from the current study varied by +/- 3 SD from ratio of 1.618 giving a mean value $=1.634+/-0.065$.

- Thus though slight variation exists, golden rectangle concept can be used for choosing dimensions of maxillary central incisors which are esthetically pleasing.

- $\quad$ No statistically significant influence of age and gender on Ratio.

- Most of the routinely used teeth sets fall in the range +/- 1 SD and all teeth sets are in the range +/- 2 SD.

\section{Clinical Implications}

Golden rectangle concept plays a valuable role in choosing the dimensions of maxillary central incisors in various treatment modalities such as;

- Restorative procedures.

- Complete dentures.

- Removable partial dentures.

- Fixed partial denture treatments.

- Implants. 
As the results of study indicate, artificial acrylic denture teeth sets such as Acrylux, Acryrock have very close golden proportion ratio to natural teeth and hence provide good esthetics. In fixed partial denture treatment procedures with gingival toned procelain, ratio helps in selection of tooth dimensions and enhances esthetics.

It enhances the esthetic value of the restoration as the concept of symmetry is incorporated in a scientific way in the teeth selection process.

Acknowledgments

The authors thank...

\section{References}

[1]. Snow SR. Esthetic smile analysis of maxillary anterior tooth width: the golden percentage. J Esthet Dent 1999;11:177-84

[2]. Lombadi RE. The principles of visual perception and their clinical application to denture esthetics. J Prosthet Dent 1973;29:358-82.

[3]. Maraquardt SR. Dr Stephan R Maraquqrdt on the golden decagon and human facial beauty. Interrview by Dr Gottlib .J Clin Orbod 2002:36:339-49.

[4]. Levin EI. Dental esthetics and golden proportion . J Prosthet Dent 1978;40:244-252.

[5]. Mange P, Belser porcelain restoration in anterior dentition : a biometric approch . Quintessence; 2002:57-96.

[6]. Owen EG, Goodacre JC, et.al A multicenter interracial study of facial appearance. Part 2 : A comparision of intraoral parameters. Int J Prosthodont 2002;15:283-8.

[7]. SterrettJD, Oliver T Robinson F, Fortson W, Kanak B, Russel CM., Wigth/Lenth ratios of normal clinical crowns of the maxillary anterior dentition in man. J Clin periodontol 1999;26:153-7.

Legents:

Fig. 1.Concept of golden rectangle.

Fig. 2.Application of golden rectangle.

Fig. 3.Digital vernier calliper.

Fig. 4.Different brands of teeth set used in study.

Fig .5.Measurement of combined width of maxillary central incisors in patient.

Fig .6.Measurement of length of maxillary central incisor in patient.

Fig .7.Measurement of combined width of maxillary central incisors on artificial acrylic teeth set.

Fig .8.Measurement of length of maxillary central incisor on artificial acrylic teeth set.

Fig. 1

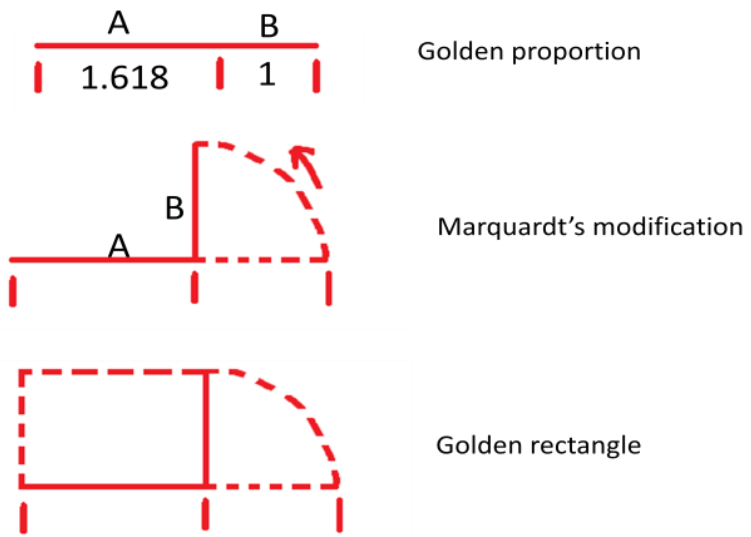

Fig.2

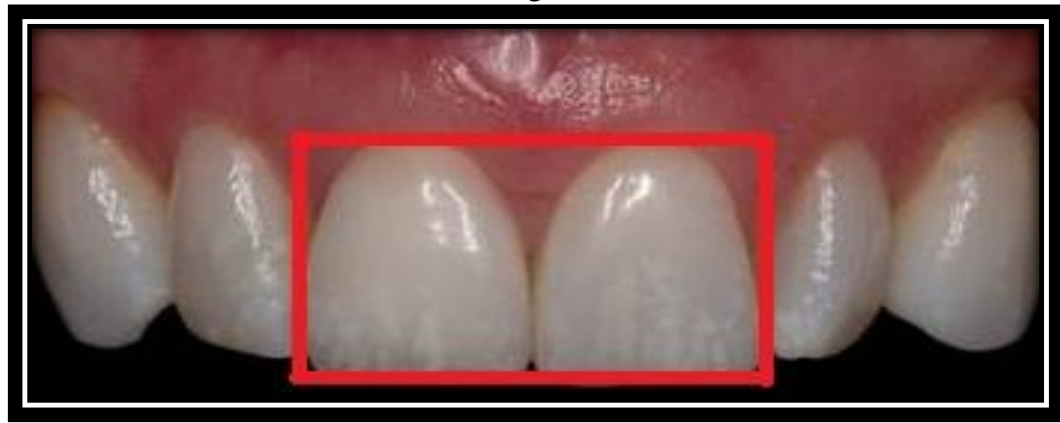

Fig.3 


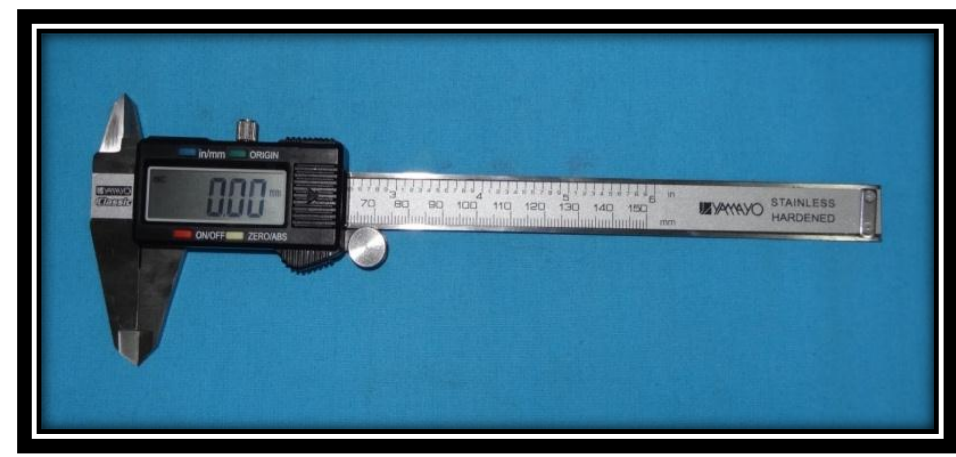

Fig. 4

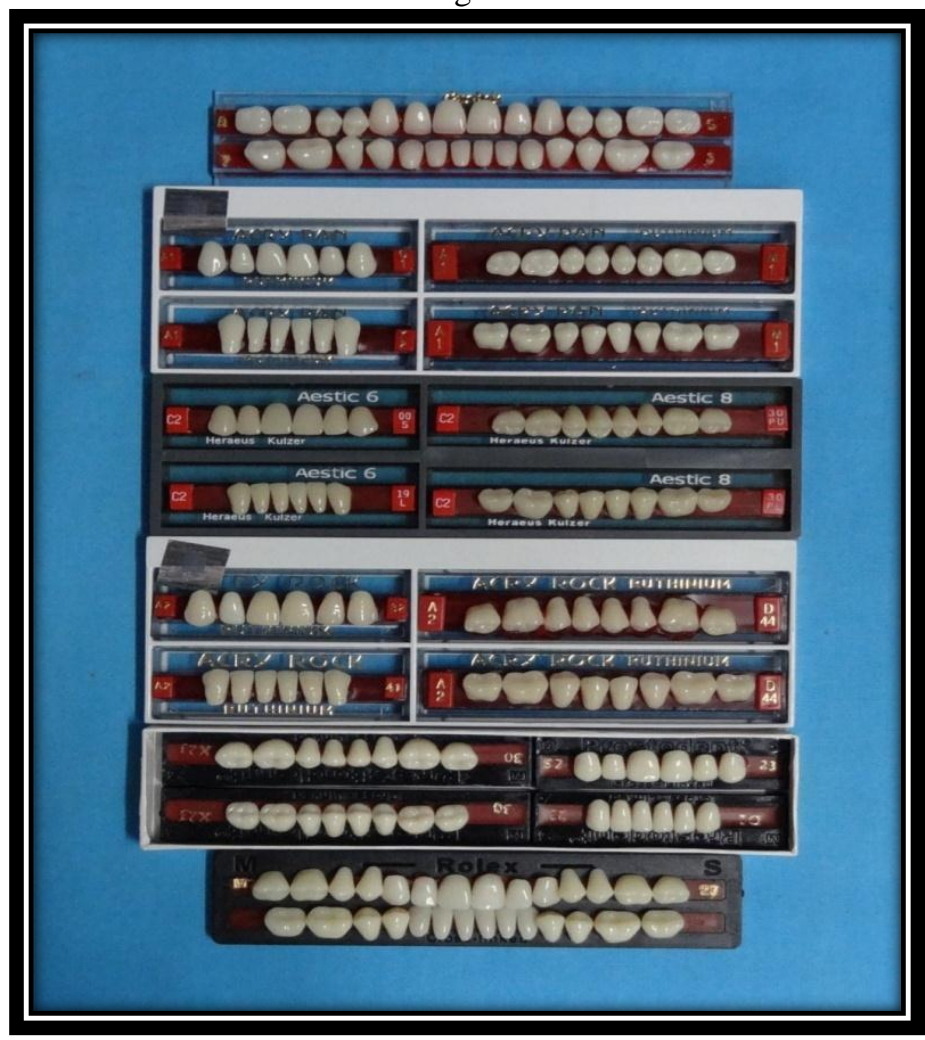

Fig. 5

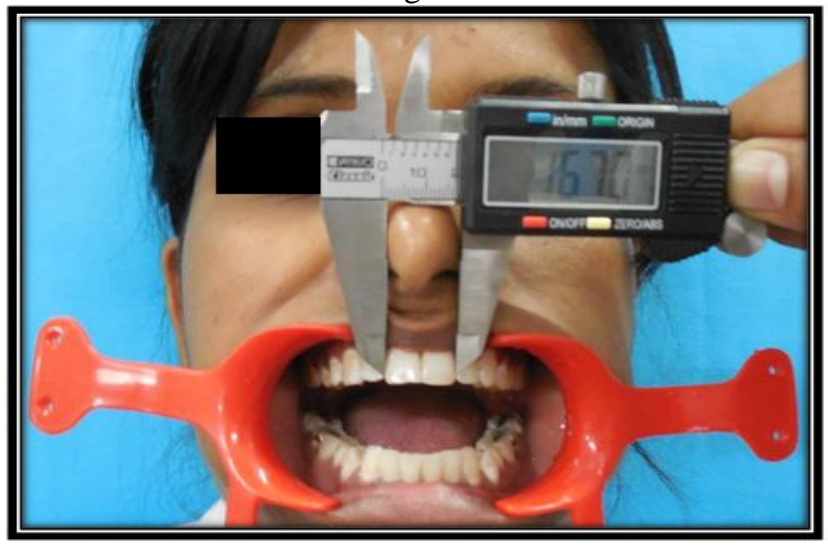

Fig. 6 


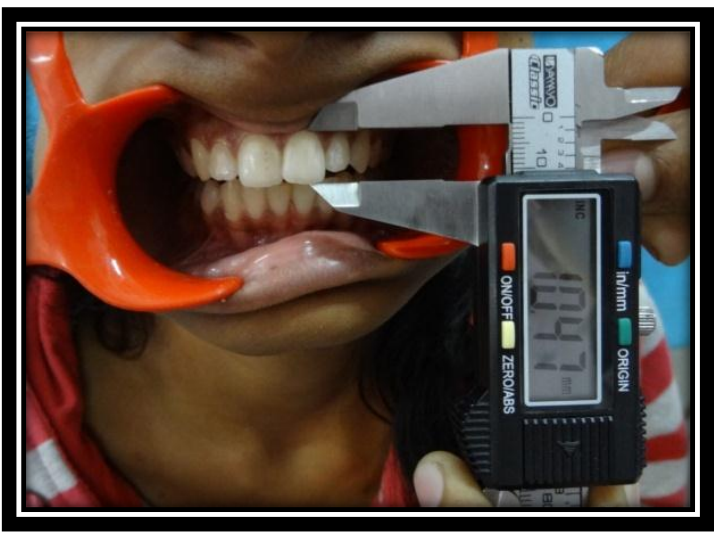

Fig.7

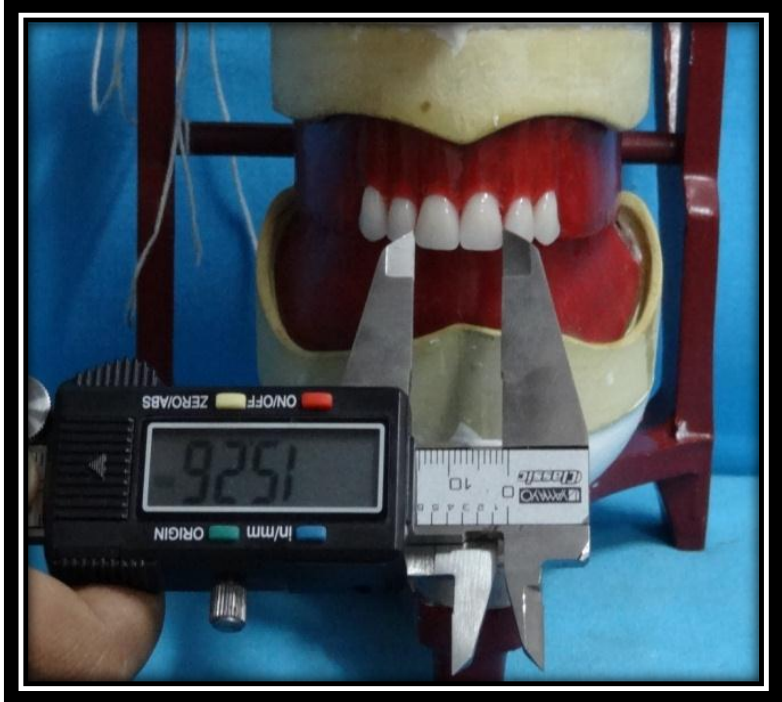

Fig.8

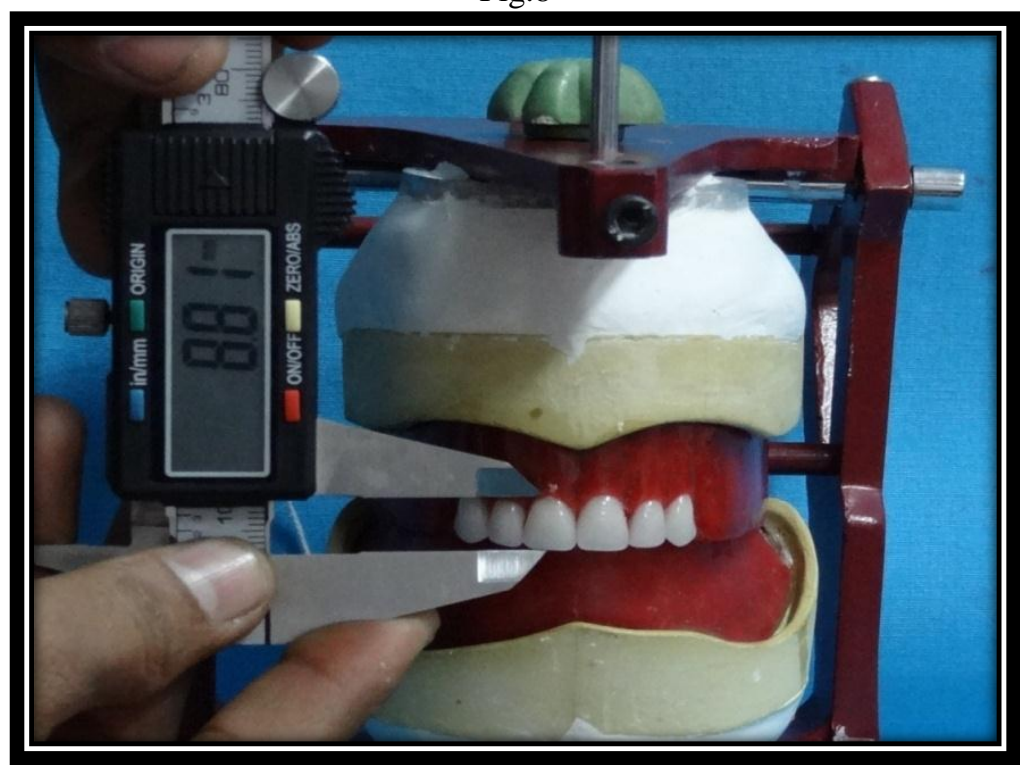

Table 1 
Golden Rectangle Ratio - How Precious Is It? : A Clinical Study

\begin{tabular}{|l|l|}
\hline PROPERTY & VALUE \\
\hline Sample size & 200 \\
\hline Mean & 1.631 \\
\hline Standard deviation & 0.070 \\
\hline Minimum & 1.473 \\
\hline Maximum & 1.804 \\
\hline
\end{tabular}

Table 2 Breakdown of subjects falling within range of Golden Rectangle Ratio :-

\begin{tabular}{|l|l|l|l|}
\hline Sr. No. & Difference & No. of cases falling in range & No. of cases not falling in range \\
\hline 1. & $+/-1$ & $32(16 \%)$ & $168(84 \%)$ \\
\hline 2. & $+/-2$ & $72(36 \%)$ & $128(64 \%)$ \\
\hline 3. & $+/-3$ & $160(80 \%)$ & $40(20 \%)$ \\
\hline
\end{tabular}

Table 3 Gender variation in combined width $(W) /$ Length $(L)$ ratio :-

\begin{tabular}{|l|l|l|l|l|l|l|l|}
\hline \multicolumn{2}{|c|}{} & \multicolumn{9}{c|}{ W/L Ratio } \\
\hline Sr. No. & Category & No. & Mean+/-SD & No. & Mean+/-SD & C ${ }^{2}$ & P \\
\hline $\mathbf{1}$ & Overall & 93 & $\begin{array}{l}1.627+/- \\
0.077\end{array}$ & 107 & $\begin{array}{l}1.634+/- \\
0.065\end{array}$ & - & - \\
& & & $1.623+/-$ & 15 & $1.619+/-$ & 0.557 & 0456 \\
\hline $\mathbf{2}$ & $+/-1$ range & 17 & 0.017 & & 0.010 & & \\
& & & $1.616+/-$ & 40 & $1.619+/-$ & 0.001 & 0971 \\
\hline $\mathbf{3}$ & +/-2 range & 32 & 0.019 & & 0.022 & & \\
& & & $1.621+/-$ & 95 & $1.647+/-$ & 1.172 & 0.279 \\
\hline $\mathbf{4}$ & $+/-3$ range & 65 & 0.040 & & 0.044 & & \\
\hline
\end{tabular}

Chart 1

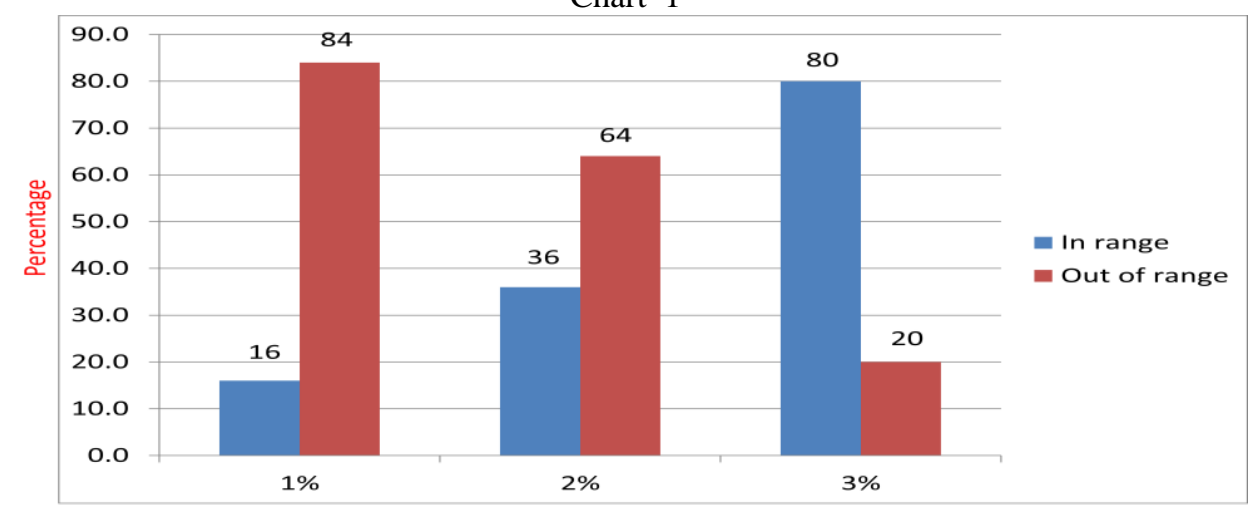

Difference from population

Table 4 Denture teeth sets falling within range of Golden Rectangle Ratio :-

\begin{tabular}{|l|l|l|l|}
\hline Sr. No. & Teeth set & Mean & Teeth set falling in range \\
\hline 1 & Dentek & 1.754 & $+/-2$ SD \\
\hline 2 & Acrypan & 1.687 & + - 1 SD \\
\hline 3 & Aestic & 1.713 & $+/-2$ SD \\
\hline 4 & Acryrock & 1.678 & + + 1 SD \\
\hline 5 & Prosthodent & 1.588 & + +/ SD \\
\hline 6 & Acrylux & 1.659 & + + 1 SD \\
\hline 7 & Rolex & 1.703 & + +/ 2 SD \\
\hline
\end{tabular}

